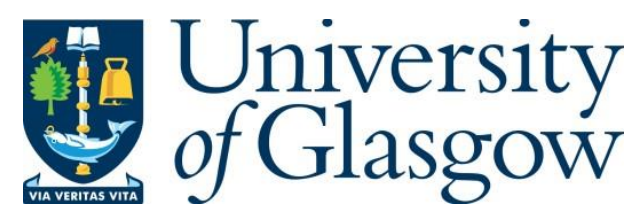

Jackson, C. and Orr, A. (2021) The embeddedness of sustainability in real estate investment decision-making. Journal of European Real Estate Research, (doi: 10.1108/JERER-09-2020-0050).

There may be differences between this version and the published version. You are advised to consult the publisher's version if you wish to cite from it.

http://eprints.gla.ac.uk/237322/

Deposited on: 24 March 2021

Enlighten - Research publications by members of the University of Glasgow http://eprints.gla.ac.uk 


\section{The embeddedness of sustainability in real estate investment decision-making}

\section{Abstract}

\section{Design/methodology/approach}

Focus groups with real estate fund managers, sustainability managers and acquisitions surveyors are undertaken to explore the adoption and implementation of environmental sustainability policies. This reveals a series of barriers to implementation and these are then explored in greater depth through a series of interviews with fund managers. This layered, qualitative approach is designed to provide detailed knowledge of practical and conceptual sustainability issues within the UK real estate market.

\section{Purpose}

The importance of real estate's sustainability rating has increased significantly. Studies undertaken in 2007 and 2016 show that, at acquisition, the rating rose from $7^{\text {th }}$ to $3^{\text {rd }}$ most important attribute. This shift in priorities parallels the RICS embracing the Ten Principles of the UN Global Compact (RICS, 2015). However, while sustainability value premia appear common in some international markets, the picture is mixed and drivers and mechanisms lack empirical investigation. This indicates potential barriers to real estate investors fulfilling both sustainability and financial objectives, explored here.

\section{Findings}

Key drivers underpinning the adoption of sustainability policies are revealed and barriers to implementation are found to relate to data on investment performance, valuation methodologies and prohibitive capex. Further, the heterogeneous, opaque and slow moving nature of the market is prohibitive and intervention is encouraged to overcome the lack of financial viability that hinders improvements.

\section{Originality/value}

Research is dominated by highly aggregated quantitative data on sustainability within commercial real estate markets. The qualitative approach used here adds new insights and value to our understanding of the embeddedness of sustainability in real estate investment decision-making. 


\subsection{Introduction}

Reporting their findings from a commercial real estate study in 2007, Jackson and Orr (2008; 2011) found that the sustainability rating of a property was a low priority for investors making stock selection decisions. Although this was a time when issues surrounding sustainability were widely debated and policies were beginning to be developed and adopted, the results revealed a pervasive lack of detailed knowledge regarding the issue. The study was repeated almost a decade later, in Q2 2016, and revealed a marked increase in the importance placed on property's sustainability rating during stockselection (see Jackson and Orr, 2018; 2019). Within a bundle of eight attributes, a property's BREEAM sustainability rating had risen from $7^{\text {th }}$ to $3^{\text {rd }}$ most important attribute, behind location and tenant creditworthiness, a clear shift in priorities.

In parallel to this, the RICS, as the real estate industry's predominant governing body, embraced the Ten Principles of the UN Global Compact, covering human rights, labour, environment and anticorruption. Furthermore, it provided guidelines to assist companies to align with those principles (see RICS, 2015). This reflects the wider, shared understanding of the need to integrate environmental sustainability and risks into business practices, within the property investment industry, noted by the UNEP-FI Property Working Group (2014) and Bosteel and Sweatman (2016). Indeed, evidence indicates firms are developing sustainability strategies, with Bilfinger GVA (2016) reporting that 84\% of investors surveyed now have these policies. However, considerable variation exists in the nature of the adopted strategies and policies (ShareAction, 2016). Furthermore, the UK appears distinct from many countries, as relatively little is known about the embeddedness of sustainability within commercial real estate investor decision-making. This is contrary to the growing body of information on sustainable design and technologies and regarding how planners, designers, developers and the wider construction industry are encapsulating sustainable practices within the development and redevelopment process.

Property investors are responsible for appraising the impact of environmental and social factors on the risk-adjusted investment returns of the assets they hold (UNEP-FI, 2012). RICS' recommended best practice is that up-to-date knowledge should be used to collect data and, where evidence exists that it affects the determination of value, this should be built into appraisals (see RICS, 2013). However, despite increasing evidence that 'sustainability premia' are being achieved on asset values in other countries, the situation in the UK is unclear and remains under-researched. Investor decision-making has been explored variously as a process (see Roberts and Henneberry, 2007) and, increasingly, in 
terms of behavioural aspects of valuation (see Northcraft and Neale, 1987, for an early example; also Diaz et al., 2004) within the overall process. However, the embeddedness of sustainability within investment decision-making, the stages at which it is considered and the mechanisms used to do so, have not been explored.

Building on the findings of Jackson and Orr $(2018 ; 2019)$, the aim of this paper is, therefore, to provide an in-depth exploration of the embeddedness of sustainability within real estate investor decisionmaking. The reference point used is the decision-making process set out by Roberts and Henneberry (2007), a rare empirically-based model. The focus of the investigations is environmental sustainability. Despite the RICS (2015) identifying that investors are a key stakeholder group with responsibilities towards environmental sustainability within the use phase of the real estate life-cycle, their behaviour and practices remain under-researched. This paper seeks to address this gap and respond to the challenge set out by the RICS (2015), to understand both the drivers and potential barriers for the adoption of the sustainability agenda. It does so through a multi-layered qualitative approach, providing a novel addition to existing studies, which are dominated by the quantitative analysis of aggregated data on investment performance and pricing. To achieve the aim of the paper, the objectives of the study are three-fold: i) to identify key themes relating to the drivers of and barriers to the adoption and implementation of environmental sustainability investment strategies in the UK, and consider their place in the decision-making process; ii) to explore those themes empirically, identifying significant issues within the industry in the strategically important area of policy implementation and thus identify possible barriers; and iii) to further explore those barriers, to enhance understanding of reasoning and complexities in the real estate sector.

The paper is structured into five sections. The next section presents a critical review of the academic and practice literature relating to environmental sustainability and this reveals key themes for exploration. These themes provide context and drivers for the adoption of sustainability polices and, additionally, reveal the need to focus on the implementation of such policies. These are mapped onto the descriptive model of the decision-making process developed by Roberts and Henneberry (2007), providing a framework for exploring the embeddedness of sustainability within the process. Section 3 contains details of the two empirical stages of the study and how they provide a progressive investigation into the embeddedness of the sustainability agenda within investment decision-making. The findings of the two stages of investigation are presented in Section 4 and this, then, leads to the conclusions and recommendations in Section 5. 


\subsection{Literature}

Definitions of sustainability or sustainable development have been debated and the triple bottom-line concept, embracing social, environmental (or ecological) and financial concerns, established. Sustainability has become embedded in the governance and reporting of large corporations (for example, Directive 2014/95/EU) and it now underpins many Environmental, Social and Governance (ESG) standards. However, focusing on real estate, while Fuerst (2015) confirms that Europe scores relatively high on 'management and policy' related to sustainability, he raises concerns that the 'implementation and measurement' of those policies is lagging. It is reasonable to assume that the determination and implementation of such policies are considered as part of an investment decisionmaking process, but the literature currently sheds little light. The empirically-based decision-making model set out by Roberts and Henneberry (2007) largely follows a normative process and comprises six stages and is used to contextualise the following review. The stages are, in the UK:

(i) Set general investment strategy;

(ii) Define detailed strategy;

(iii) Property search;

(iv) Analysis and trade-off;

(v) Consult clients and/or management; and

(vi) Investment selection.

Within the literature explored here, the last two stages are largely subsumed within the analysis and trade-off stage, often forming part of an iterative process, or, in some cases, are not touched upon. Therefore, they are not considered as distinct parts of the decision-making process here, being largely encapsulated within the earlier stages or outside the scope of this paper.

Looking at the first two stages, general and detailed strategy setting, ESG and related Corporate Social Responsibility (CSR) and Responsible Property Investment (RPI) concepts embrace the social, environmental and financial aspects of responsible investment, yet fulfilment across these areas may be in conflict. Indeed, conflicts between financial and environmental responsibilities are cited as the reason for not implementing more environmental sustainability investment strategies. For example, a decade ago, sustainability was a low priority among UK investors (Dixon et al., 2008; Jackson and Orr, 2008; 2011), as 'the financial case for sustainability remains unproven' (Dixon et al., 2008, p. 406). Around that time, Sayce et al. (2007) revealed property investment professionals believed that 
sustainability ${ }^{1}$ had little impact on rents and yields in the sector, although the majority did think it would within five years. However, by contrast, investors in the US reported that risk and return, outperformance and business advantage were the main reasons for engaging in RPI (Pivo, 2008), although the picture was not entirely clear as with some citing concerns over risk and return and inefficient financial performance as a serious impediment. More recently, Sullivan et al. (2015) and CRREM (2019) challenge this and argue it need not be the case if a long-term perspective is taken. Similarly, the RICS $(2015$, p. 8) asserts that adoption of responsible and sustainability corporate strategies 'will not only deliver social, environmental and ethical value, but is essential for long-term financial success'.

Moving to the property search and analysis and trade-off stages (third and fourth stages), Fuerst and McAllister (2011a) discuss that financial returns are delivered via higher occupancy rates; lower utility costs (especially in gross leases); decreased rates of depreciation; and reduced regulatory obsolescence. They also explain that the 'bundle of benefits' which sustainable properties offer should raise demand for occupation, thus attracting a lower risk premium during the pricing process. However, empirical exploration of such factors or, indeed, risk premia is almost entirely missing from the literature, and CRREM (2019) notes that carbon risk remains inadequately and inconsistently priced into investment decision-making.

Rather than focusing on risk premia, the majority of studies focus on capital value premia, being the outcome of the pricing process rather than exploring the process itself. Many studies find evidence that investors are paying more for sustainable buildings. In the US, capital value premia of $16 \%$ are found by Eichholtz et al. (2010); Miller et al. (2008) estimate 6\%-11\% premia for green-rated office properties; and Pivo and Fisher (2010) estimate a 12.5\% premium on Energy Star-rated office properties. Fuerst and McAllister (2011a; 2011b) find price premia of 18\%-26\% in the US, depending on the accrediting body (or $28-29 \%$ if double labelled), with higher premia for higher levels of certification, although they did not find this link in the UK. Also in the UK, Chegut et al. (2011) find market value premia of $27-43 \%$ for BREEAM rated buildings. Newell et al. (2014) find value premia of up to $9.4 \%$ for the highest NABERS-rated office buildings in Australia, and $11.8 \%$ for offices with the top three Green Star ratings, with increasingly smaller premia for the lower NABERS ratings, but ratings differ fairly markedly across the three markets they examined. In addition to exploring value

\footnotetext{
${ }^{1}$ Sayce et al. (2007) narrowed a previous sustainability definition to measurable metrics that essentially captured financial and environmental features.
} 
premia, Newell et al. (2014) is a rare study that also focuses on yield premia, finding that, as the NABERS rating increases, risk premia fall.

As with risk premia, these (and other) studies suggest various drivers for the value premia, yet without fully exploring them offer limited explanation on how sustainability is incorporated into the analysis and trade-off stage. In terms of financial drivers, these tend to relate to occupier demand and wider risk reduction. Indeed, higher occupancy rates do appear to contribute to improved investment characteristics, with Pivo and Fisher (2010) and Fuerst and McAllister (2011a) finding a slight, but statistically significant, $1 \%$ occupancy rate premium for Energy Star rated office buildings in the US. In terms of raising occupier demand, the literature suggests that tenants, keen to reduce utility costs, improve productivity and achieve reputational benefits, are willing to pay more for energy efficient buildings. Indeed, Fuerst and de Wetering (2015) estimate BREEAM-rated buildings across the UK on average achieve rents $23-26 \%$ higher than non-BREEAM rated buildings. Chegut et al. (2014) find similar premia in London, but question whether this would hold across geographically diverse markets. Rental premia, ranging from $3 \%$ to $20 \%$ have also been found in the US and Australia (Eichholtz et al., 2010; Wiley et al., 2010; Newell et al., 2014). In the US, Fuerst et al. (2014) found these 'green' premia to be greater than the cost savings brought about by the enhanced running efficiency of the building, indicating tenants are not driven by cost savings alone. Explanations relating to the concept of wellbeing have been suggested by Ries et al. (2006), Miller et al. (2009) and Leishman et al. (2012).

In terms of wider risk reduction, Ellison et al. (2007) define sustainability as a set of changing commercial property investment risks, reducing rates of depreciation, obsolescence and capital expenditure. Lorenz and Lützkendorf (2008) agree, citing increasing investment performance and more profitable and marketable assets. Eichholtz et al. (2010) discuss investor demand, suggesting possible drivers include lower running costs, corporate image and lower risk due to extended building life. They suggest that the value premia for green buildings is greater than the quantified saving in costs, mirroring Fuerst et al. (2014)'s finding in the user market. However, the CRREM (2019) study into the integration of carbon risk into corporate strategies argues that the disregard of embedded carbon has created an 'undue bias' in favour of new green buildings, and that the lack of evidence regarding value premia and cost savings is making the case for the green retrofitting of existing buildings hard to prove.

When formulating the business case for a property during the analysis and trade off stage, consideration of partnership, collaborative working and trust-building initiatives between landlords 
and tenants (such as Memorandums of Understanding or more formal 'green leases') may underpin expected risk reduction and enhanced values. For example, Miller and Buys (2008) find lower investment risk because tenants are more committed to remaining where they trust the landlord, although smaller tenants were less willing to be involved in such initiatives.

Overall, while this review reveals increasingly strong engagement with the sustainability agenda, it also reveals a marked lack of empirical investigation into the way in which it is implemented within the decision-making process. The literature is dominated by quantitative examination of outcomes, rather than processes, and by suggestions of drivers rather than empirically-based findings. Furthermore, the financial case is ambiguous and the UK evidence remains contradictory and partial. In line with the first research objective, a number of key themes for further investigation relating to the drivers of, and barriers to, the adoption and implementation of environmental sustainability strategies are identified. The first three are (1) Strategy setting and policy; (2) Financial drivers; and (3) Non-financial drivers. Considering and situating them within the decision-making process, these predominantly relate to the first two stages of Roberts and Henneberry's (2007) framework, the highlevel general and then detailed setting of strategy. A fourth key theme is also revealed, being (4) Implementation and measurement, which can be mapped onto the 'analysis and trade-off' stage of the decision-making framework. This series of issues spans much of the decision-making process and, in reality, each cannot always be clearly and uniquely considered within a single phase of the process. The issues require investigation to advance understanding and, as such, form the basis for the following empirical stage.

\subsection{Methods}

A mixed, layered qualitative research approach underpins this study, in pursuit of the aim to provide an in-depth exploration of the behaviour and practices of real estate investor decision-making around the sustainability agenda. Here, primary data are collected using two dovetailing methods - focus groups and interviews - thereby providing a more robust understanding of the views and experiences of professional participants by triangulating results (Hesse-Biber, 2010).

The focus groups were used to explore the four key themes, as identified in section 2 and in line with the second research objective. Thus, a series of questions were put to the focus groups, exploring each key theme in turn, enabling detailed exploration of the underlying gaps in knowledge identified in the literature review. To ensure focus, each question was cross-referenced internally both to one of the 
three UN Principles on the Environment and also to the first two key issues highlighted by the RICS (2015) as within the use phase of the real estate life cycle (being transparency and disclosure, and environmental stewardship).

Purposive sampling, following the principles set out by Kemper et al. (2003) for single stage sampling, was used to recruit focus group membership spanning a range of property investment professionals that play a role in the real estate use phase (following RICS, 2015). The target participants were drawn from a list of fund managers, investment managers, asset managers, investment analysts and investment policy makers identified from property company lists, linkedin and professional networks accessible to the researchers via SPR, RICS and IPF. In all 337 potential applicants were invited by email to take part in the focus groups with 104 follow up telephone calls made, with final selection based on positive responses and securing representative groups spanning a range of roles. The research took place during a period of high market activity, with many respondents unable to guarantee availability, with others unable to be reached and/or preferring not to respond. A number forwarded the request to their in-house sustainability specialist, but the groups were carefully constructed to avoid bias towards such specialists.

Following Jackson and Orr (2018; 2019), participants were selected with a UK focus to their investment activities. A total of 13 participants took part in two focus groups, coming from four broad types of firm, being: commercial real estate consultancy (3), development and investment company (2), investment and asset manager (7) and a privately owned property company (1). Ten of these specialised across all commercial real sectors, one specialised in the industrial sector, and two in retail. In terms of role, there were four fund managers (FGFM), one portfolio/asset manager (PAM), three investment analysts (IA), two asset managers (AM), one sustainability consultant (SC) and two sustainability property investment policy-makers (SPIP). While the selection of participants from the short list was random and no incentive was given to encourage participation, possibility of selfselection bias remained in the final selection as the professionals who engaged with the exercise tended to be those with a genuine interest in sustainability, albeit they encompassed a range of roles. The participants effectively spanned all the traditional commercial property sectors, bringing them together to examine their collective perceptions and experiences of environmental sustainability and sustainable buildings, and draw out areas of shared and contrasting understanding. The dynamics in such group interactions can also generate new thinking about an issue and result in a much more indepth discussion. 
The focus group meetings took place in a neutral location, the RICS headquarters in London. The two hour meetings began with a structured opening task, with participants discussing whether they agreed or disagreed with statements about sustainability, to relax and encourage them to feel comfortable with proffering differing views. The moderator used the same semi-structured topic guide to facilitate and structure the discussions amongst participants, and to enable similarities and differences to be drawn out in the analysis between the groups. The focus groups were video- and audio-recorded, transcribed verbatim, coded and the content analysed using an abductive thematic analytical approach. The coding was undertaken independently by two researchers who later compared results, the purpose being to verify the interpretation of meaning and enhance the reliability of the data (Cope and Kurtz, 2016). The four broad themes, which emerged from the review of the literature, where used as a first step in the analysis process to deductively code the data and then the second stage in the analyses identified eight sub-themes that inductively emerged from the data. These sub-themes and how they nest within the main themes are illustrated by the coding hierarchy in Figure 1(a).

As also shown in Figure 1(a), and in line with the second research objective, a number of barriers to implementation emerged. Analysis of the data suggests that financial, pricing and viability issues represent barriers to the further implementation of sustainability strategies. These findings emerge as four barriers and, given the strategic importance of implementation across stakeholder groups, their further investigation forms the second stage of the research methodology, as shown in Figure 1(b). This is in pursuit of the third research objective, to further explore barriers to implementation to enhance understanding of reasoning and complexities in the real estate sector. 


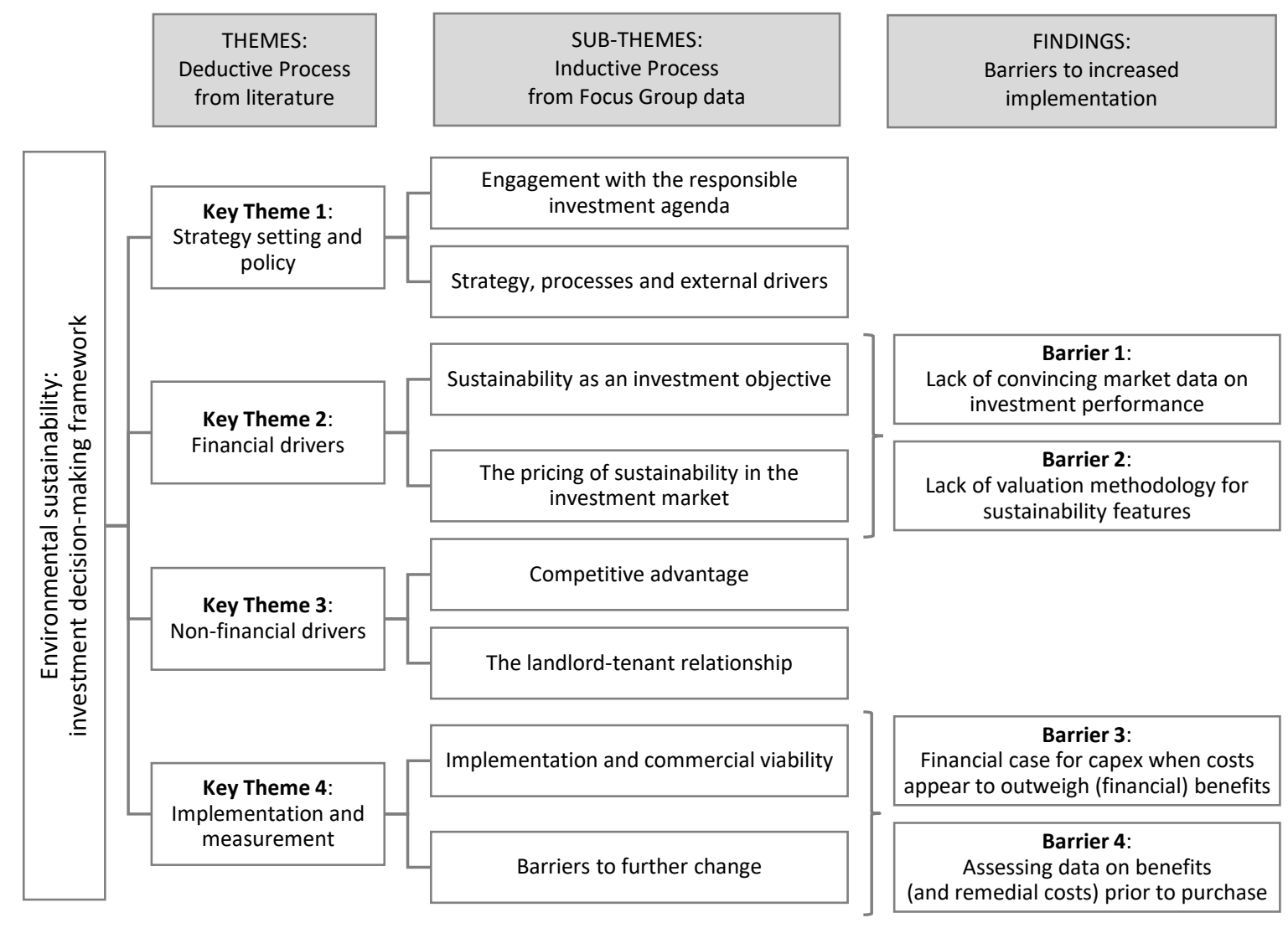

Figure 1(a). Exploring key themes and identifying drivers and barriers using focus groups.

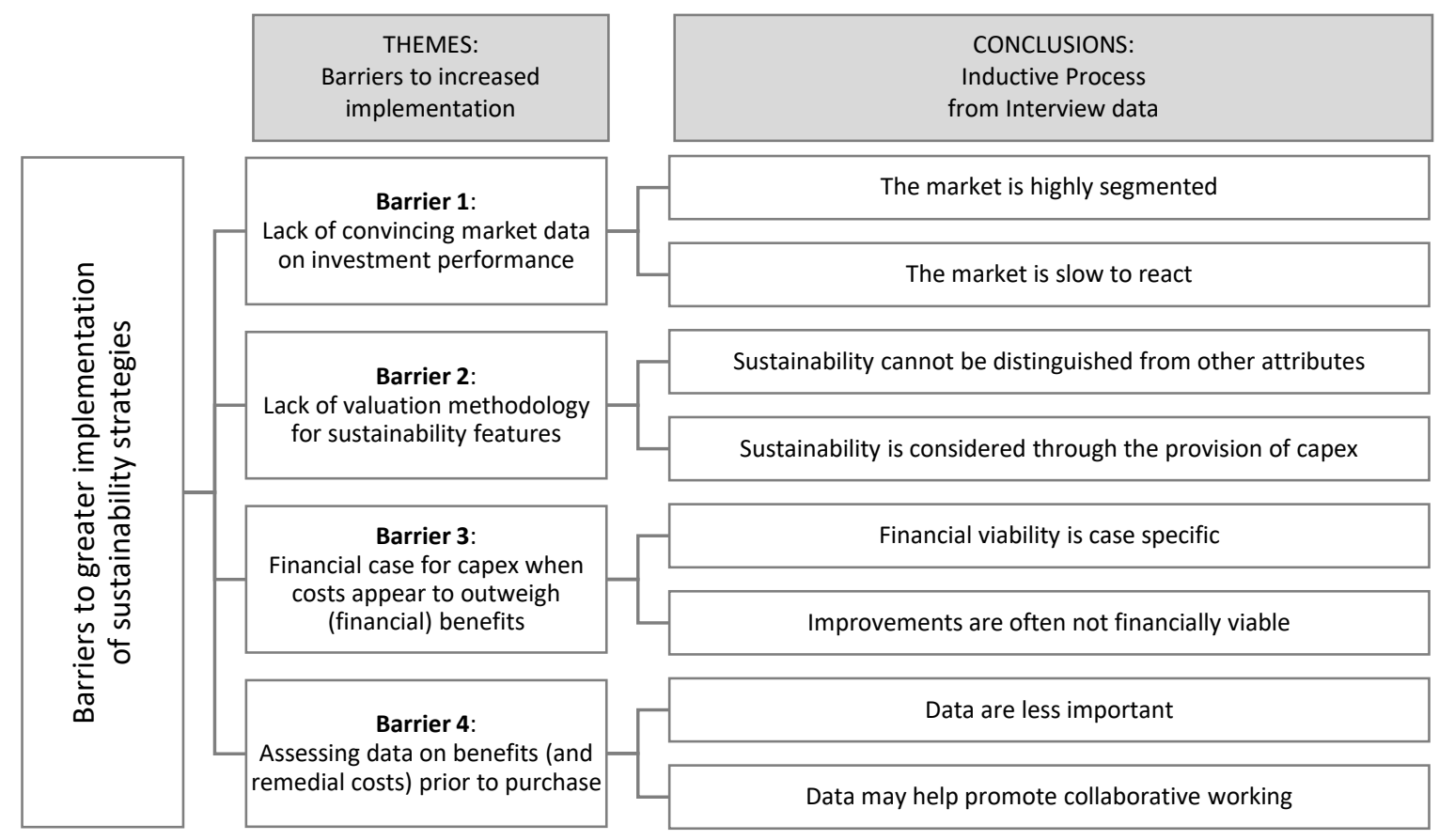

Figure 1(b). Exploring the barriers using in-depth interviews.

Figure 1. Hierarchical coding tree. 
This second stage, designed as part of a sequential mixed method process (following Morse, 2015), involved in-depth semi-structured telephone interviews with fund managers (IFM) who were purposively sampled and did not attend the focus groups. Each telephone interview lasted roughly 30 minutes during which participants were asked a standard set of semi-structured questions. The questions explored each of the barriers in turn, initialling asking for opinions of the findings from the focus groups and literature, then exploring the answers in more depth to uncover detailed opinions, explanations and experiences. These tightly focused one-to-one structured conversations enabled a significant depth of exploration. Fund managers were targeted at this stage as, while they work alongside a range of related professional specialists (represented in the focus groups), they need a holistic understanding and have responsibility for investment performance. The interviews could, therefore, not only probe their own decision-making, but gain insights into communications across the team. The sample was constructed to cover a broad range of fund types, with respondents working for fund managers, investment managers or a property trust, but respondents were encouraged to draw upon their experience generally, to give breadth of coverage, felt important at this early stage of this strand of work within the discipline. Interviews were undertaken and the sample expanded until no new insights were revealed, thereby indicating saturation had been reached. In total, eight interviews were undertaken, appropriate within the context of a small specialist population and an area of investigation refined through the earlier focus groups (Collins, 2015). The findings presented below for both stages of the analysis rely on the transcribed conversations.

\subsection{Results}

\subsection{Exploring the key themes and identifying drivers and barriers using focus groups}

\subsubsection{Key theme 1: Strategy setting and policy}

The analysis of the focus group transcriptions identified two sub-themes in relation to sustainability strategies within the investment decision-making process, presented below.

\section{Engagement with the responsible investment agenda}

Awareness of and engagement with sustainability has both increased and broadened from environmental concerns to encompass the ESG agenda, especially for companies with a high public profile, such as REITs. This has led to specialist roles being developed. ESG includes ethical issues such as behaviour towards tenants, shareholders, contractors, suppliers and beneficial social impacts 
(including creation of local employment), health and wellbeing and 'wellness'. These factors are increasingly promoted to tenants because they affect workforce productivity and retail footfall, local/general job creation, contributing to sustainable communities and place-making.

Although for many there is a desire to avoid risks associated with not doing anything, and CSR was stated to be on everyone's agenda (IA3), explicit sustainability policies vary across sectors. The industrial sector was thought by at least three respondents to be less likely to strive for excellence, because assessment criteria (e.g. EPC ratings) are insufficiently sophisticated for the specifics of the sector. This resonates with the IPF (2017) finding that energy consumption is specific to manufacturing and trade processes. However, this does not preclude asset managers from taking a bottom-up approach to ensure (sometimes beyond minimum) compliance with legislation (AM1). Where asset management is not a priority, such as for companies that buy and sell quickly, less importance tends to be placed on sustainability policies (FGFM2).

\section{Strategy, processes and external drivers}

There are clear regulatory drivers affecting sustainability strategies and processes, including the Energy Act 2011, which came into force in April 2018. The growth in certification schemes is also pushing sustainability up the agenda. Indeed, respondents also felt that going beyond minimum compliance would give future advantage, as minimum ratings are expected to 'inevitably' rise. However, respondents discussed the potential for legislation to lead to purposeful inaction. For example, if a property becomes unlettable due to its EPC rating, there may be an economic case for 'moth-balling' the property, or delaying refurbishment, even with short-term financial penalties for non-compliance (PAM). However, reputational impact, recognised widely as a serious concern, remains a strong disincentive for such tactics (SPIP1).

Internal processes in the development of sustainability strategies span a range of stakeholders to ensure they are fit for purpose and informed both by top-down fund-level strategies and bottom-up asset-level drivers. Consistency regarding the setting, communication and implementation of strategies is key, ensuring expectations and evaluations are clear, and objectives aligned. Asset managers (and property managers and facilities managers) are seen as very important actors - the 'executive armour' (SPIP1) - with close working relationships with tenants and detailed experiential knowledge. They can be involved in sourcing assets, developing the strategy/business plan preacquisition and implementation post-acquisition (FM4, SPIP2). 
Having a sustainability strategy was identified as important to attract clients, with perceived benefits including image and as a means to future-proof assets. Investors and some tenants are more frequently requiring firms to report good standings in indicators such as the UN PRI Reporting Framework and GRESB and to demonstrate embeddedness within the investment process (SPIP2). These reporting requirements can lead to internal reporting processes, and KPIs, increasing data requirements on managing agents and the need for dedicated in-house teams. Meaningful analyses (year-on-year comparison) are gradually becoming possible, enabling policy re-evaluation (SPIP1). GRESB has become established and accepted within the industry and, for some, is no longer seen as voluntary - some clients use GRESB to rank funds to assess where to invest. One respondent stated that clients wouldn't even consider a company if it wasn't submitting to GRESB and that some clients actively seek an improvement in the achieved score, effectively used as '[a] stick [...] rather than a [...] carrot' (SPIP2). However, these developments are not industry wide; such mechanisms are less likely in smaller firms (AM1).

\subsubsection{Key theme 2: Financial drivers}

Focusing on direct financial drivers, the following two areas emerged from the discussions.

\section{Sustainability as an investment objective}

Overall, sustainability has little relationship with the setting of financial investment objectives because its contribution is financially uncertain and difficult to quantify. Sustainability characteristics have more of a direct impact on operational efficiencies than on income generation. However, sustainability can affect the likelihood of achieving financial objectives (SPIP2). For example, for funds that seek secure and long-term income streams, desirable tenants are attracted by stock with high sustainability characteristics (IA3).

Fiduciary duty remains the predominant concern of fund managers and, if conflicts arise between satisfying financial and sustainability objectives, financial objectives dominate:

'I think ultimately you have to justify that there's commercial return there. Ultimately, when you're presenting something to your investment board or whoever it is, you have to be able to justify that it stacks up... You just cannot [do] something because ... it's going to be green' (IA1). 


\section{The pricing of sustainability in the investment market in the UK}

The literature identifies market stratification in Australia and North America based on sustainability premia. However, focus group participants agreed that there was limited or no evidence for this in the UK. The situation is complex, with other economic and market factors felt to dominate pricing and, by some, also liquidity. For example, newer buildings tend to have higher sustainability ratings and higher values, but causation is muddled by build-cost inflation, both general inflation and due to enhanced sustainability measures. Other factors such as obsolescence, building age and tenant retention are also inter-tangled and so, without clear data and an established methodology, there is nervousness about quantifying the impact of sustainability features. The discussions revealed complex and, at times, contradictory accounts regarding the extent to which environmental sustainability is embedded within property valuations. When asked whether there is evidence that sustainability is being incorporated, respondents were divided, with responses ranging from 'No, definitely not, I don't think' (AM2) to 'Yeah, definitely' (SPIP2). There was consistency, however, in that rental levels reflect an overall assessment of the building rather than its sustainability characteristics.

In fact, whereas new buildings have higher levels of sustainability to be fit-for-purpose (IA1), older buildings may suffer from Sayce's (2013) 'brown-discount', reflecting the capex required to implement improvements (SPIP2; FGFM2; FGFM3). Similarly, participants also cited evidence of tenants demanding specific EPCs on refits, or rent-free periods to take on buildings with low EPCs; all of which are reflected in the financial appraisal of a building, through either capex or perceived financial risk.

Knowledge of market pricing thus informs the setting of detailed strategy, but is also very much encapsulated within the analysis and trade-off phase. It is likely that, over time, there will be an iterative relationship between the two phases, reflective of any movement in market practices.

\subsubsection{Key theme 3: Non-financial drivers}

As identified above, sustainability has increasingly become part of wider ESG objectives and, ultimately, may result in financial gains. Here, two elements are identified. However, crucially, 'there's intangible benefits which have knock-on financial impact but there's no payback on that' (SPIP2). 


\section{Competitive advantage}

The main driver for the adoption of wider ESG strategies is reputation. This dominated all discussions about non-financial drivers, summed up by IA3, 'it's very, very important to be seen on the market as a responsible investor'.

Reputation underpins core business activities by increasing marketability to clients. Similarly, the increasing public awareness of sustainability means a strong and visible policy can be very important in securing investment for some funds.

\section{The landlord-tenant relationship}

Tenants are increasingly recognising the importance of environmental sustainability, and it has become embedded within strategic targets, especially those of high profile tenants. This affects their space requirements (FGFM2) and they 'are expecting you to have those green credentials in there' (IA1). For investors, aligning their strategies accordingly can be a significant business advantage and drive their own policy development (IA3), although where target occupiers have different priorities, a bare minimum compliance strategy is optimum.

Tenants in the office sector have been strongest in driving the sustainability agenda, confirming Fuerst and McAllister (2011a). The retail sector has seen changes over the last five years to a position of almost 'nil resistance' towards green clauses (FGFM3), with the industrial sector lagging, as above.

Where landlord-tenant strategies are aligned, a trusting relationship depends on all parties being fully briefed, willing and capable of managing the building to the desired standard, as needed to maintain certification levels. Occupiers' head offices are generally on-board with sustainability initiatives, but there can be challenges with on-site management, including the effective use of an Environmental Building Management System. Fund managers may have to resort to lease clauses to legally force cooperation, ensure compliance and protect asset values. However, securing an income stream takes priority over pushing for compliance.

As above, there has been a move away from landlord-led improvements, towards working more closely with tenants to promote wellness and associated productivity benefits. Health and wellbeing are captured by BREEAM, and have risen in the strategic priorities of tenants (IA1; SPIP2), with landlords finding this to be more effective in involving tenants than cost savings associated with EPCs, although not all are engaged. 


\subsubsection{Key theme 4: Implementation and measurement}

Throughout the discussions participants talked about frustrations, barriers and tensions when implementing sustainability strategies. The sub-themes identified here all relate to commercial viability, identified as one of the most important factors restricting the pace at which environmental sustainability measures are implemented.

\section{Implementation and commercial viability}

Assessing the commercial viability of implementing environmental sustainability strategies is more important when acquiring standing stock than when developing a new building, due to the costs of retrofitting. This can be more problematic outside of core prime markets, where building stock is likely to be less sustainable and to have lower values.

Accurate operational data and capex figures can identify areas for improving operational performance and inform assessments of commercial viability. However, data are not often forthcoming, or requested, prior to transacting, with approximations used in appraisals. The usefulness of such data was questioned, as it is dependent on the building management strategy and tenant use. Postacquisition sees a marked improvement in data collection, although where poor collaborative relationships exist this 'becomes a whole world of pain' (SPIP2). While experience can reduce the perceived risk in undertaking works, until there are improvements in quantitative data on occupational efficiencies, 'it's always going to be a situation where you're going to struggle to get [sustainability] expenditure to stack up' (PAM).

Difficulties in establishing commercial viability for sustainability works were discussed, with a lack of market rental and value premia for sustainable buildings frequently cited as resulting in financial and sustainability conflicts (PAM). Improvements are usually undertaken on a case-by-case basis (IA1), with the pay-back period for capex both crucial and difficult to estimate. Aligning pay-back periods with lease lengths is important, but can be difficult to achieve. Ultimately, it is difficult to produce highly accurate cost-benefit assessments of capex as

'until you've got the hard data, serious capex and future-proofing is a very difficult assessment to make... Making the viability case or commercial argument for it is still quite difficult' (FGFM1). 


\section{Barriers to further change}

Aside from commercial viability, leasing and design were identified as barriers to further change. In terms of leasing, changes in leasing terms between, for example, older leases falling under the provision of the 1954 Landlord and Tenant Act and newer 'green leases/clauses' can produce a clash and represent an effective barrier to implementation (SPIP1, FGFM1). Respondents reported (sometimes quite vehement) resistance from tenants at times with regard to some green clauses, with engagement through cooperation seen as more effective and desirable:

'I don't believe that a lease is the right place for a lot of the kind of green clauses that over the last five years have come into leases ... it's down to the relationship of the FM or the property manager and the tenant and they help work with us or not, irrespective of what's in the lease' (SPIP2).

In terms of building design, some respondents feel there is potential for improvements, where sustainable building technology should be focused on how the building is actually going to perform in use. Architectural and design practices are seen to recognise sustainability as part of their core discipline, but some suggest that new design is simply following building regulations. One participant suggested:

'we should be designing for the way the building's actually going to perform and I think when we make that transition, that will make a big difference ... I don't think that we're designing any better' (SPIP2).

Participants stated that the design process is not sufficiently joined-up, is adversarial and often required greater input and cost than should be expected. FGFM3 and SPIP2 stated that flexibility and adaptability are important in future-proofing assets, with cost an over-riding barrier to further change. Participants thought that further advances in technology are needed to achieve greater levels of sustainability/self-sufficiency. Unreliable technology and high specialist maintenance costs were also cited as barriers to implementing environmental sustainability initiatives. 


\subsubsection{Findings - four barriers to implementation}

The findings from the focus groups provide empirical evidence from the UK to confirm Fuerst's (2015) conclusion, that 'management and policy' is generally widespread, but that 'implementation and measurement' is lagging. The findings reveal frustrations, barriers and tensions in the implementation of sustainability initiatives, especially through the investigation of Key Themes 2 and 4 , where it is clear that issues around 'financial drivers' and 'implementation and measurement' hold the key to hampering implementation, as shown in Figure 1(a). Implementation is of utmost importance within the sustainability agenda and the data reveal four barriers:

Barrier 1: there is a lack of convincing market data on investment performance in the UK - this contrasts with much of the literature, which largely focuses on aggregated data;

Barrier 2: there is a lack of methodology for the explicit inclusion of sustainability features into valuations and appraisals - the lack of uniformity is clear and, furthermore, with RICS guidance setting out that sustainability must be included where there is market evidence, further investigation is needed;

Barrier 3: there are difficulties in making the financial case for capex when costs appear to outweigh (financial) benefits - this challenges the belief that investors will benefit from reduced regulatory obsolescence and also inhibits steps to move beyond minimum compliance; and

Barrier 4: there are issues with assessing data on benefits (and remedial costs) prior to purchase visual surveys and estimates of capex are relied upon, which may impact on the implementation of business plans.

Enabling the implementation of environmental sustainability strategies is of strategic importance across stakeholder groups, including central government, industry governing bodies, fund managers and investors, and all concerned with environmental sustainability issues. Therefore these four barriers are analysed in greater depth, through in-depth interviews with fund managers, with the findings set out below and conclusions presented in italics. 


\subsection{Exploring the barriers to implementation using in-depth interviews}

\subsubsection{Barrier 1: Lack of convincing market data on investment performance}

Interviewees noted that valuers identified a lack of market data that sustainability commands higher values. Two clear areas emerged to explain this. The first is that the market is highly segmented due to the heterogeneous nature of property investment, including sector, lot size, tenant type, investor/fund type and regional location. Unless sustainability is a key priority in each category, respondents felt that neither rental nor capital values will show a premium. For example, a prime office, with a large floorplate, with a large corporate occupier, in central London, owned by a "green fund" would be assumed to have high sustainability characteristics, but, if just one of those factors differs, then financial viability is impacted and works are unlikely to be implemented. Examples of differences include that some overseas buyers are 'looking at a totally different investment metric' (IFM4); and that many tenants' priorities are elsewhere:

'We don't tend to see much in the way of any demand from the tenants that we engage with for buildings that are particularly green. I'm struggling to think of a single incident or incidence where that's been the case' (IFM6).

Much of the discussion revolved around the second area to emerge, which is that the market is slow to react, with IFM1 explaining that, 'as ever real estate lags behind and it's a slow-moving beast'. Many set out that the regulatory environment, where a single-let property is on a FRI lease, effectively blocks the owner from making alternations to plant or utilities provision. This effectively removes a significant proportion of existing stock from the debate, exacerbated by long lease terms, largely unique to the UK.

A number of respondents voiced opinions that sustainability is only beginning to come through; green premia (or green liquidity) may occur further down the line as the market is a bit behind where it should be. Not all agree and IFM1 suggests that more sustainable properties are already becoming more liquid than others, as demand for them increases. However, IFM6 describes that many investors are waiting for tenant demand to move towards sustainability and 
'without that, I think you're kind of ploughing a bit of a lonely furrow if you're looking to plough ahead with green initiatives because you may find you're out on a bit of a limb or you're ahead of actually where the market is.'

\subsubsection{Barrier 2: Lack of valuation methodology for sustainability features}

The interviewees were not confident of the finer details of the valuation process, undertaken by external valuers. They described close communications, however, and, through that, they confirmed the view of the focus groups, voicing doubts that they had seen any evidence that rents or values were higher because of sustainability features:

'I think you'd be hard-pressed to find evidence that you could point categorically to, to indicate that a premium had been paid' (IFM3)

'It's not something that our valuers openly talk about because I don't think they see any impact at all either' (IFM6)

'It's not giving a valuation boost you know, we don't get any valuation benefit valuing a BREEAM Excellent building ... [and] ... [sustainability] would probably be at the bottom of the list of things affecting valuation' (IFM7).

Respondents acknowledged that highly sustainable properties would commonly have higher values, but they attributed this to the fact that these properties are generally of a higher standard, better designed (and often newer) than other properties. Thus, the clear message is that sustainability cannot be distinguished from other attributes - the value of a property reflects the whole package and this seriously hinders the financial case for proposed works.

Respondents felt that yields were not being adjusted to reflect any perceptions of risk reduction or future-proofing through enhanced levels of sustainability. Instead, the consistent approach is that sustainability is considered through the provision of capex and this determines the viability of a proposed purchase. However, some revealed a possible contradiction, discussing that scenario appraisals sought to balance capex on sustainability works against higher rents that could be achieved, thus indicating that there are, in fact, links, presumably supported by market evidence. However, this type of finely tuned evidence is 
'probably a bit more thumb in the sky, there's nothing specific for you to hang your hat on, like lots of things with commercial property, it's a touchy-feely game rather than a mathematical equation. You've got to find a buyer at the end of the day and a seller' (IFM4).

\subsubsection{Barrier 3: Financial case for capex when costs appear to outweigh (financial) benefits}

Respondents consistently reported that, when considering the provision of capex for improvement works, whether for a proposed purchase or held stock, financial viability is case-specific. This is as expected, yet discussions highlighted sensitivity, with little variation in costs yet significant variation in the rate of pay-back because of the heterogeneous nature of the sector (as above), with phases of the market cycle often cited as crucial to feasibility.

Fund strategy is also important when making a case for improvements, with IFM7 describing the importance of selling the fund as "green". Funds, such as charities, were often cited as making irrecoverable expenditure in pursuit of strategies for the common good and associated wider accountability. IFM6 discusses that it is important 'to be seen to be doing the right thing ... [but] it doesn't always mean that doing the right thing is cost-effective'.

Spending can often be defensive, to maintain value, rather than to enhance it. This does not just relate to changing EPC requirements, pertinent at the time of the interviews, but includes basic maintenance. Defensive spending often results in sustainability improvements, however, due to advancements in plant, windows, $\mathrm{AC}$ systems, for example, reinforcing that sustainability cannot be distinguished from other attributes. It can also relate to the strength of the market, as above, as sometimes

'something has changed in a market, rents have fallen or whatever and capex isn't earnings-accretive. I mean there'll be some situations where we have to spend the money and not get a return on it, if we're going to preserve the value of the investment' (IFM8).

There were mixed responses relating to the over-arching issue of whether improvements are often not financially viable, as fund managers tend to limit their aspirations, aligning proposals to market 
circumstance. Even regarding simpler improvements, such as replacing windows, views were mixed, ranging from this being straight-forward works, to frustration that even this was not financially viable in some markets.

\subsubsection{Barrier 4: Assessing data on benefits (and remedial costs) prior to purchase}

This final barrier relates to the pre-acquisition phase and the availability of sustainability performance data, and revealed contrasting views. Some respondents confirmed the views of the focus groups and reported that such data are less important and, indeed, may not be accessed; other attributes such as location were considered to dominate decisions. Furthermore, some explain that the spec of the plant itself is more important, rather than direct data usage. Others reported difficulty in accessing the data, with IFM2 stating that 'you don't have any entitlement to that information as a purchaser'.

An alternative view is that such data may help promote collaborative working, if it helps identify the potential for cost savings. This may be through changing utilities provider, or working with a specialist environmental firm for the provision of energy-saving products. Some described accessing these data as increasing in importance, perhaps driven by reporting requirements such as GRESB. Changes through collaborative working, noted by IFM2 and IFM8, may influence the rental value, in turn influencing the capital value, although IFM8 noted that this was a hope for the future and, currently, it is 'theoretical, at this point, let me tell you'.

\subsection{Conclusions}

Responding to evidence that the sustainability agenda has risen significantly in importance in the real estate acquisition decision-making process in the UK over the last decade, this paper has sought to provide an in-depth exploration, focusing on environmental sustainability, using a two-stage qualitative research approach. This has produced insights not possible through the quantitative approach that dominates this important agenda, focusing on drivers, processes and barriers, rather than outcomes that tend to be the focus of quantitative studies. Thus, it also responds to the RICS' (2015) assertion that a key challenge for the real estate profession is to understand drivers and barriers to greater sustainability. The findings reveal that there has been a positive step-change in the embeddedness of sustainability in real estate investment decision-making, yet it is not pervasive across all parts of the industry and, furthermore, there are significant barriers to its implementation. 
This is key during the analysis and trade-off stage, and is the most fraught with uncertainty and frustration.

Overall, in terms of strategy setting and policy, the findings indicate that a cultural shift has taken place over the last decade, supporting the finding by Jackson and Orr $(2018,2019)$. Environmental sustainability (and wider ESG) strategies are at the core of many businesses. For some, reporting is undertaken routinely and the accompanying transparency scrutinised by clients and some tenants and peers. Sustainability achievements form internal KPIs and new specialist roles have been established. However, there is inconsistency away from core markets and large firms and much of this variation is linked to client priorities, tenant demand and the financial viability of improvement works.

Motivations predominantly relate to regulation and accountability, in turn linked to reputation and competitive advantage. This adds new evidence to the discussions of Eichholtz et al. (2010) and Fuerst et al. (2014). Some investor clients and tenants are driving strategy and reporting; fund managers are increasingly expected to evidence responsibility and sustainability achievements. Further motivations include the protection of asset value and future-proofing against tightening legislation, with policy uncertainty being identified by Jackson and Orr (2019) and CRREM (2019) as a significant driver of real estate investor and tenant behaviours.

Wider ESG policies were not the focus, but the findings clearly indicate that they are increasingly common, yet compliance may not have direct financial drivers or demonstrable pay-back. Indeed, the results suggest that reputation and 'doing the right thing' are more important drivers to some investors (charities were identified here) and tenants than cost savings. However, although reputational effects associated with such policies cannot be entirely separated from financial benefits, the lack of direct pay-back may mean that policies are difficult to fully implement. This is not just because of financial viability concerns, but also potentially because of the self-limiting nature of behaviour indicated by some respondents.

In terms of analysis and trade-off, barriers to implementation predominantly relate to financial viability and sector issues. Frustrations and tensions are clear. Segmentation of assets, actors and markets, is hugely important for financial viability, especially with little variability in costs, but significant variability in value, exacerbated during market phases. Through identifying and investigating barriers to implementation, the following conclusions are suggested. 
The property market is inherently highly segmented and slow to react. To enable greater implementation of environmental sustainability strategies, it is suggested that central incentivisation and subsidy schemes are considered, recognising imbalances between costs and values across markets. This could also draw in industry practices that see pay-back periods as prohibitively long, to enable the views of Sullivan et al. (2015), the RICS (2015) and CRREM (2019) to be embraced, regarding a long-term perspective. Furthermore, the results suggest that some investors and occupiers are not engaging with the sustainability agenda. Some occupiers are effectively insulated from investor policies by the UK leasing structure. Further analysis is needed, with government and industry bodies taking the lead in engaging a wider cross-section of investors and occupiers to improve coherence and overcome blocks to wider implementation.

The findings that sustainability cannot be distinguished from other attributes and is considered through the provision of capex within valuations perhaps indicate that sustainability should not be viewed as separate, but embedded within investment. Isolating it may be unhelpful and counterproductive if this results in the negative views expressed here, that it does not positively affect value, that rental and capital value premia do not exist and there is no impact on yields, contrary to the literature. However, the literature almost exclusively relies on quantitative analysis of aggregated data, with the qualitative insights presented here adding to understanding of this complex area. Indeed, Newell et al. (2014) note that their analyses cannot distinguish between management and sustainability premia, an example of the multiple interlinked aspects of real estate. There are perhaps contradictions evident in some of the views expressed here, that sustainability improvements do not enhance value, yet capex needs to be viewed against higher rents. Subsuming sustainability within established considerations such as obsolescence, specification and routine maintenance could reflect and represent normalisation.

If the barriers to implementation could be tackled as above, this may lead to the further conclusions that financial viability is case specific and improvements are often not financially viable being overcome, in turn. The findings suggest that this could be further enabled if design improvements can be more collaborative with the investment industry.

Through steps to enable financial viability, as suggested above to include targeted incentivisation and subsidy schemes, alongside research into widening and enabling participation, it could be that greater and more meaningful data provision becomes the norm, overcoming the conclusion that data are less important and further enhancing that data may help promote collaborative working. Better data 
standards and systems are necessary. Thus, while the discussion here reveals that there has been a positive and significant step-change in embedding sustainability within investor decision-making over the last decade, it also reveals notable and complex barriers. It is suggested that, while there are clear and considerable complexities within the area of environmental sustainability and property investor decision-making, it may be that targeted actions could be the catalyst for change and that these would be most effectively embraced during the analysis and trade-off stage. Overall, through the qualitative methods employed, this paper has provided a richer and in-depth exploration of how the industry is engaging with the sustainability agenda. Such studies add powerful insights into complexities underlying quantitative headlines.

\section{Acknowledgements}

The authors would like to sincerely thank the study participants. Only through their time and engagement can primary data be used to evaluate and progress the sustainability agenda.

\section{Author Contributions}

Cath Jackson: Conceptualization, Methodology, Investigation - focus groups and interviews, Formal analysis - focus groups and interviews, Writing - original draft; Writing - review \& editing, Project Administration, Funding Acquisition; Allison Orr: Conceptualization, Methodology, Investigation focus groups, Formal analysis - Focus Groups, Joint writing of original draft. 


\section{References}

Bilfinger GVA (2016) Green to Gold. Insight into investment attitudes, Summer 2016, Bilfinger GVA, London.

Bosteel, T. and Sweatman, P (2016) Sustainable Real Estate Investment - Implementing the Paris Climate Agreement: an action framework, A Joint Report of the Climate Strategy and Partners (Investor Group on Climate Change, IIGCC, Investor Network on Climate Risk, UPEP FI, PRI and RICS), February 2016.

Chegut, A., Eichholtz, P. and Kok, N. (2011), The Value of Green Buildings: New Evidence from the United Kingdom, Working Paper, Maastricht University Netherlands, available at:

http://immobilierdurable.eu/images/2128_uploads/Chegut_Eichholtz_Kok_green_value_in_the_uk. pdf (accessed 29 July 2016).

Collins, K. (2015) Advanced sampling designs in mixed research: current practices and emerging trends in the social and behavioral sciences, Chapter 15 in Tashakkori A, Teddlie C, editors, Handbook of Mixed Methods in the Social and Behavioral Sciences, Edition 2, Sage: Thousand Oaks, pp. 353-378.

Cope, M. and Kurtz, H. (2016) Organizing, coding and analyzing qualitative data, Chapter 36 in, Clifford, N., Cope, M., Gillespie, T. and French, S., Key Methods in Geography, $3^{\text {rd }}$ Edition, SAGE Publications Ltd, pp. 647-664.

CRREM (2019) Carbon Risk Integration in Corporate Strategies within the Real Estate Sector, CRREM Report No. 2, December 2019, Wörgl: Austria.

Diaz, J., Gallimore, P. and Levy, D. (2004) Multicultural examination of valuation behaviour, Journal of Property Investment and Finance, 22, 4, pp. 339-346.

Dixon, T., Colantorio, A., Shiers, D., Reed, R., Wilkinson, S. and Gallimore, P. (2008) A green profession? A global survey of RICS members and their engagement with the sustainability agenda, Journal of Property Investment and Finance, 26, 6, pp. 460-481.

Eichholtz, P., Kok, N. and Quigley, J. M. (2010) Doing well by doing good? Green office buildings. American Economic Review, 100, 5, pp. 2492-2509.

Ellison, L., Sayce, S. and Smith, J. (2007) Socially Responsible Property Investment: Quantifying the Relationship between Sustainability and Investment Property Worth, Journal of Property Research, 24, 3, pp. 191-219.

Fuerst, F. (2015) The Financial Rewards of Sustainability: A Global Performance Study of Real Estate Investment Trusts. University of Cambridge.

Fuerst, F. and McAllister, P. (2011a) Eco-labelling in commercial office markets: Do LEED and Energy Star offices obtain multiple premiums? Ecological Economics, 70, 6, pp. 1220-1230.

Fuerst, F. and McAllister, P. (2011b) Green Noise or Green Value? Measuring the Effects of Environmental Certification on Office Values, Real Estate Economics, 39, 1, pp. 45-69.

Fuerst, F., Oikarinen, E., Shimizu, C. and Szumilo, N, (2014) Measuring 'Green Value': An International Perspective; RICS Education Trust Research Series, September 2014, RICS: London. 
Fuerst, F. and van de Wetering, J. (2015) How does environmental efficiency impact on the rents of commercial offices in the UK? Journal of Property Research, DOI: 10.1080/09599916.2015.1047399.

Hesse-Biber, S. (2010) Qualitative approaches to mixed methods, Qualitative Inquiry, 16, 6, pp. 455468.

IPF (2017) Costing Energy Efficiency Improvements in Existing Commercial Buildings, IPF: London.

Jackson, C. and Orr, A. (2008) Investor Decision-making and Property Attributes, Final Report to the Education Trust of the Royal Institution of Chartered Surveyors, RICS Education Trust Research Series, October 2008, RICS: London.

Jackson, C. and Orr, A. (2011) Real estate stock selection and attribute preferences, Journal of Property Research, 28, 4, pp. 317-339.

Jackson, C. and Orr, A. (2018) Changing priorities in investor decision-making: the sustainability agenda, RICS Research Trust, London.

Jackson, C. and Orr, A. (2019) Investment decision-making under economic policy uncertainty, Journal of Property Research, 36, 2, pp. 153-185.

Kemper, E. A., Stringfield, S. and Teddlie, C. (2003) Mixed methods sampling strategies in social science research, Chapter 10 in Tashakkori A, Teddlie C, editors, Handbook of Mixed Methods in the Social and Behavioral Sciences, Sage: Thousand Oaks, pp. 273-296.

Leishman, C., Orr, A. and Pellegrini-Masini, G. (2012) The Impact of Carbon Emission Reducing Design Features on Office Occupiers' Choice of Premises. Urban Studies, 49, 11, pp. 2419-2437.

Lorenz, D. and Lützkendorf, T. (2008) Sustainability in property valuation: theory and practice. Journal of Property Investment and Finance, 26, 6, pp. 482-521.

Miller, E. and Buys, L. (2008) Retrofitting commercial office buildings for sustainability: tenants' perspectives, Journal of Property Investment \& Finance, 26, 6, pp. $552-561$.

Miller, N., Spivey, J. and Florance, A. (2008) Does green pay off? Journal of Real Estate Portfolio Management, 14, 4, pp. 385-399.

Miller, N.G, Pogue, D., Gough, Q.D. and Davis, S. M. (2009) Green buildings and productivity, Journal of Sustainable Real Estate, 1, pp 65-89.

Morse, J. (2015) Procedures and practice of mixed method design: maintaining control, rigor, and complexity, Chapter 14 in Tashakkori A, Teddlie C, editors, Handbook of Mixed Methods in the Social and Behavioral Sciences, Edition 2, Sage: Thousand Oaks, pp. 339-352.

Newell, G., MacFarlane, J. and Walker, R. (2014) Assessing energy rating premiums in the performance of green office buildings in Australia, Journal of Property Investment and Finance, 32, 4, pp 352-370.

Northcraft, G. B. and Neale, M. A. (1987) Experts, Amateurs, and Real Estate: An Anchoring-andAdjustment Perspective on Property Pricing Decisions, Organizational Behaviour and Human Decision Processes, 39, pp. 84-97. 
Pivo, G. (2008) Exploring responsible property investing: a survey of American executives, Corporate Social Responsibility and Environmental Management, 15, 4, pp 235-248.

Pivo, G. and Fisher, J.D. (2010) Income, value and returns in socially responsible office properties, Journal of Real Estate Research, 32, 3, pp. 243-270.

RICS (2013) Professional Guidance, Global Sustainability and commercial property valuation, RICS Guidance Note, Global, 2nd edition, October 2013.

RICS (2015) Advancing Responsible Business Practices in Land, Construction and Real Estate Use and Investment, RICS, London.

Ries, R., Bilec, M.M., Gokhan, N.M. and Needy, K.L. (2006), The economic benefits of green buildings: a comprehensive case study, The Engineering Economist, 51, 3, pp. 259-95.

Sayce, S. (2013) Sustainability and real estate values: time for the agenda to move on?, Property Management, 31, 3, pp. 274-275.

Sayce, S., Ellison, L. and Parnell, P. (2007) Understanding investment drivers for UK sustainable property, Building Research and Information, 35, 6, pp. 629-643

ShareAction (2017) Lifting the Lid: Responsible Investment Performance of European Asset Managers: The 2017 ShareAction Survey, March 2017.

Sullivan, R., Martindale, W., Feller, E. and Bordon, A. (2015) Fiduciary Duty in the 21st century, Report of UNEP FI, PRI,UNGC and UNEP Inquiry 2015.

UNEP-FI (2012) Responsible Property Investment Produced by the Property Working Group of the United Nations Environment Programme Finance Initiative What the leaders are doing, 2nd edition, UNEP, Geneva.

UNEP-FI Property Working Group (2014) Sustainability Metrics: Translation and impact on property investment and management, Main report of the Property Working Group of the United Nations Environment Programme Finance Initiative, May 2014.

Wiley, J., Benefield, J. and Johnson, K. (2010) Green design and the market for commercial office space, Journal of Real Estate Finance, 41, 4, pp. 228-243. 